\title{
Editorial
}

\section{Clozapine of treatment resistant-schizophrenia: what are the actual advances?}

Schizophrenia is a devastating mental illness affecting individuals at the height of their potential, crippling people in adolescence or early adult life. It probably causes more suffering and distress, and blights more lives than any form of cancer. ${ }^{1}$ The economic burden of schizophrenia is significant, incorporating the costs of direct health provision, social services, and the loss of productive individuals from the economy. A recent analysis ${ }^{2}$ estimated the cost of schizophrenia to the United Kingdom (UK), performing model simulations of 7,500 cases that incorporated direct and indirect cost to society and the known disease course. The total cost to society attributable to an annual cohort of newly diagnosed patients was estimated at $£ 862$ million. This is greater than the cost of cardiorespiratory disorders (due mainly to inpatient hospital stays, and the social and health costs of inadequately controlled symptoms). Importantly, antipsychotic drugs and adjunctive medications accounted for only $2 \%$ of the total expenditure. Treatments that reduce hospitalization and potentially enable patients to return to active employment could significantly reduce the burden of schizophrenia.

Although psychosocial interventions are fundamental, antipsychotic treatment is the mainstay of care for schizophrenia, and yet approximately one-third of patients fails to respond to conventional medication. Until recently, the prognosis for such treatment-resistant patients was uniformly gloomy. Clinicians tried high-dose typical antipsychotic strategies, or augmentation with mood stabilizers, and in very severe cases electroconvulsotherapy (ECT). If these treatments failed, the patient was consigned to a lifetime of custodial care, with little freedom from illness, drug side effects and poor quality of life.

The advent of clozapine has revolutionized this picture. The demonstration by Kane et al, ${ }^{3}$ that clozapine was effective in this treatment-resistant group is a landmark in the literature. Even with very stringent criteria for treatment-resistant schizophrenia, 30\% of the patients responded within 6 weeks of clozapine treatment, compared with only $4 \%$ of chlorpromazine-treated subjects. These data, together with the demonstration that efficacious blood monitoring for granulocitopenias is feasible, led to approval of clozapine for treatment-resistant schizophrenic patients in 1989 in the U.S., and in many other countries in subsequent years. The early findings were massively replicated in the literature. Wahlbeck et $\mathrm{al}^{4}$ conducted a meta-analysis including 2,350 participants in 30 trials on the effectiveness of clozapine in schizophrenia. They confirmed that clozapine is more effective than typical antipsychotic drugs in producing clinical improvement, including a significant delay in relapse rates. Prospective studies of clozapine outpatients have also demonstrated significant improvements in quality of life, reduction in the utilization of medical resources ${ }^{5}$ and reductions in suicide rates. ${ }^{6}$

Patients with schizophrenia need indefinite continuous maintenance treatment. Wahlbeck et $\mathrm{al}^{4}$ showed that clozapine beneficial effect over conventional antipsychotic drugs increases over time, since long-term studies showed a larger benefit for clozapine than short-term studies. Meltzer ${ }^{7}$ reported a 12-month follow-up of 85 treatment-resistant patients taking clozapine, which showed significant improvement in positive and negative symptoms, quality of life, cognitive function, extrapyramidal symptoms (EPS), and tardive dyskinesia. Readmissions to hospital and family burden were markedly reduced. Inpatient hospital stay, the social and health costs of inadequately controlled symptoms represent a much greater expenditure when compared to antipsychotic medication costs.

Psychopathology is not the only highly predictive measure of the benefits of antipsychotic treatment. Perhaps the greatest impact of clozapine has been on patient's quality of life and social functioning, allowing them to return from the 'twilight zone' of illness to their family, friends and work.

Clozapine has been in use at the Maudsley Hospital since 1990. The drug has been remarkably successful in producing remission even in the most severely ill individuals. A specialized Clozapine Clinic was set up dedicated to managing maintenance therapy of patients treated with the drug. The clinic was highly successful and found impressive rates of compliance in these subjects, who are renowned for their poor adherence to treatment. ${ }^{8}$ A pharmacoeconomic evaluation of the clinic $^{9}$ revealed that improved therapeutic response in these severely ill patients translated into lower relapse rates and bed usage, and was economically viable. The centralized approach yields benefits in terms of concentrating expertise, and fostering a supportive network for patients and their caretakers.

The impact of clozapine has also revitalized the search for antipsychotic drugs with lesser toxicity, but comparable efficacy and the same favorable EPS profile. A number of secondgeneration antipsychotic drugs have been made available. These are now included as first-line options for the treatment of schizophrenia, ${ }^{10}$ as well as being increasingly suggested as possibly useful in other disorders. ${ }^{11}$

Clozapine is not established as a medication for every schizophrenic patient. The risk of agranulocitosis has made its use highly 
regulated over the last decade. ${ }^{8,12}$ It is restricted to patients that fail to respond to two or more adequate antipsychotic trials (at least 6 weeks), including a trial with a safer atypical antipsychotic. However, the close monitoring of blood white cell counts efficiently decreases the risk of granulocitopenias, ${ }^{13,14}$ making the inconvenience of such risks to be clearly outweighed by the drug's clinical benefits. ${ }^{4}$

Although the use of clozapine may continue to be regulated, there is a clear worldwide trend towards making its use increasingly more accessible to the patients that are likely to benefit from it. ${ }^{15,16}$ The same tendency is seen with secondgeneration antipsychotic drugs. ${ }^{17}$ Such reasoning should also apply to Brazil, a country where medical and social costs due to schizophrenia are very significant, and where clinical experience and expertise have accumulated over the years on the use of clozapine and other atypical antipsychotics for schizophrenia. ${ }^{18}$ If the treatment with clozapine is to be controlled, regulations should encourage treatment in eligible patients, instead of creating obstacles. Within that context, guidelines for treating resistant schizophrenia such as those

\section{References}

1. Kendell RE. Schizophrenia. In: Kendell RE, Zealley AK, eds. Companion to psychiatric studies. 5th ed. London (UK): Churchill Livingstone; 1993. p. 326-97.

2. Guest JF, Cookson RF. Cost of Schizophrenia to UK Society- an incidence based cost-of-illness model for the first 5 years following diagnosis. Pharmacoeconomics 1999;15:597-610.

3. Kane JM, Honigfeld G, Singer J, et al. Clozapine for the treatment-resistant schizophrenic. Arch Gen Psychiatry 1988;45:789-96.

4. Wahlbeck K, Cheine M, Essali A, Adams C. Evidence of clozapine's effectiveness in schizophrenia: a systematic review and meta-analysis of randomised trials. Am J Psychiatry 1999;156:990-9.

5. Daniel DG, Whitcomb SR. Treatment of refractory schizophrenic patient. J Clin Psychiatry 1998;59:13-21.

6. Meltzer HY. Suicide and schizophrenia: clozapine and interSePT study. J Clin Psychiatry 1999;60(12):47-50.

7. Meltzer HY. Dimensions of outcome with clozapine. Br J Psychiatry 1992;160(17):46-53.

8. Munro J, O'Sullivan D, Andrews C, Arana A, Mortimer A, Kerwin R. Active monitoring of 12760 clozapine recipients in the UK and Ireland. Br J Psychiatry 1999;175:576-80.

9. Aitchison KJ, Kerwin RW. Cost-effectiveness of clozapine. A UK clinicbased study. Br J Psychiatry 1997;171:125-30.

10. Pearsall R, Glick ID, Pickar D, Suppes T, Tauscher J, Jobson KO. A new algorithm for treating schizophrenia. Psychopharmacol Bull 1998;34:349-53. recently put forward for public consultation by the Brazilian Ministry of Health ${ }^{19}$ should be criticized. The excessively strict inclusion criteria for clozapine use in their proposition (such as a long history of the disorder, and the previous use of unnecessarily high doses of conventional antipsychotics) might prevent appropriate treatment for suitable patients. The accompanying guidelines for the use of other atypical antipsychotics, including olanzapine and risperidone, are equally restrictive. ${ }^{20}$ The scientific evidence reviewed in this text suggests that guidelines with such degree of strictness could be considered 'mal practice', since they would institute an enormous amount of patient and family suffering, together with unnecessary expenditure of public money.

Rodrigo A Bressan and Lyn S Pilowsky

Atypical Antipsychotic Clinic, Maudsley Hospital, Section of Neurochemical Imaging, Institute of Psychiatry

Geraldo Busatto Filho

Departamento de Psiquiatria da Faculdade de Medicina da Universidade de São Paulo

11. Ghaemi SN, Goodwin FK. Use of atypical antipsychotic agents in bipolar and schizoaffective disorders: review of the empirical literature. J Clin Psychopharmacol 1999;19:354-61.

12. Alphs L, Anand R. Clozapine: the commitment to patient safety. J Clin Psychiatry 1999;60(12):39-41.

13. Atikin K, Kendall F, Gould D, Freeman H, Lieberman J, O'Sullivan. Neutropenia and agranulocytosis in patients receiving clozapine in the UK and Ireland. Br J Psychiatry 1996;169:483-8.

14. Honigfeld G. Effects of the clozapine national registry system on incidence of deaths related to agranulocytosis. Psychitr Serv 1996;47:52-6.

15. Kane JM. Managment strategies for the treatment of schizophrenia. J Clin Psychiatry 1999;60(12):13-7.

16. Naber D. Optimising clozapine treatment. J Clin Psychiatry 1999;60(12):35-8.

17. Frangou S, Lewis M. Atypical antipsychotics in ordinary clinical practice: a pharmaco-epidemiologic survey in a south London service. Eur Psychiatry 2000;15:220-6.

18. Oliveira IR. Antipsicóticos atípicos: farmacologia e uso clínico. Rev Bras Psiquiatr 2000;22(suppl 1):38-40.

19. Secretaria de Assistência à Saúde. Portaria $\mathrm{SAS} / \mathrm{N}^{\circ} 286$. Ministério da Saúde: Diário Oficial da União; 15/8/2000.

20. Portaria $S A S / n^{\circ} 347$, Secretaria de Assistência à Saúde, Ministério da Saúde, Diário Oficial da União, 15/8/2000. 